2016-11-05

Factors limiting the establishment of canopy-forming algae on artificial structures

\title{
Cacabelos, E
}

http://hdl.handle.net/10026.1/9610

\subsection{6/j.ecss.2016.08.036}

ESTUARINE COASTAL AND SHELF SCIENCE

Elsevier BV

All content in PEARL is protected by copyright law. Author manuscripts are made available in accordance with publisher policies. Please cite only the published version using the details provided on the item record or document. In the absence of an open licence (e.g. Creative Commons), permissions for further reuse of content should be sought from the publisher or author. 
2 Disclaimer:

3 This is a pre---publication version. Readers are advised to refer to the final published 4 version.

5 Year 2017, Estuarine and Coastal Shelf Science 181, 277-283

7 Factors limiting the establishment of canopy-forming algae on artificial structures

8 Eva Cacabelos ${ }^{a}$, Gustavo M. Martins ${ }^{a, b}$, Richard Thompson ${ }^{c}$, Afonso C. L. Prestes ${ }^{a}$,

9 José Manuel N. Azevedo ${ }^{a}$, Ana I. Neto ${ }^{a}$

$10{ }^{a} \mathrm{cE} 3 \mathrm{c}$ - Centre for Ecology, Evolution and Environmental Changes / Azorean Biodiversity

11 Group, and Universidade dos Açores, Departamento de Biologia, 9501-801 Ponta

12 Delgada, São Miguel, Azores, Portugal.

$13{ }^{\mathrm{b}}$ CIIMAR-Centro Interdisciplinar de Investigação Marinha e Ambiental, Rua dos Bragas

$14 \quad 289$, Porto, Portugal

$15{ }^{\mathrm{c}}$ Marine Biology and Ecology Research Centre, Plymouth University, Plymouth PL4 8AA,

16 Devon, UK

17 * Corresponding author: e-mail: evacacabelos@yahoo.es

18 Abstract

19 Macroalgal canopies are important ecosystem engineers, contributing to coastal

20 productivity and supporting a rich assemblage of associated flora and fauna. Yet, they are

21 often absent from infrastructures such as coastal defences and there has been a

22 worldwide decline in their distribution in urbanised coastal areas. The macroalga Fucus

23 spiralis is the only high-shore canopy forming species present in the Azores. It is widely

24 distributed in the archipelago but is never found on coastal infrastructures. Here we 
evaluate factors that may potentially limit its establishment on artificial structures. A number of observational and manipulative experiments were used to test the hypotheses that: (i) limited-dispersal ability limits the colonisation of new plants onto artificial structures, (ii) vertical substratum slope negatively influences the survivorship of recruits, and (iii) vertical substratum slope also negatively influences the survivorship and fitness of adults. Results showed that the limited dispersal from adult plants may be a more important factor than slope in limiting the species ability to colonise coastal infrastructures, since the vertical substratum slope does not affect its fitness or survivorship.

Keywords: coastal defences; intertidal; rocky shores; macroalgae; benthic communities; coastal urbanization

\section{Introduction}

Canopy-forming algae are key species on intertidal rocky shores (Jonsson et al., 2006) as they can provide shelter from environmental stressors (e.g. desiccation or ultraviolet radiation) for a diverse range of flora and fauna. By doing this, they play an important role in regulating community structure, nutrient cycling and primary production and therefore their conservation should be considered a priority (Bertocci et al., 2011; Perkol-Finkel and Airoldi, 2010; Perkol-Finkel et al., 2012). Despite their importance, marine canopy-forming algae have declined over the past decades (Perkol-Finkel and Airoldi, 2010; Strain et al., 2015), with major implications for the biodiversity and rocky reefs ecosystem goods and services (Airoldi and Beck, 2007; Smale et al., 2013; Voerman et al., 2013). There is thus a clear need to understand the drivers underlying their loss (Perkol-Finkel and Airoldi, 2010), the mechanisms that confer them stress tolerance (but see Martínez et al., 2012), and how the relative balance of physical (e.g. wave action) and biological factors (e.g. 
grazing) control their establishment and persistence (Davison and Pearson, 1996; Jonsson et al., 2006). Evidence worldwide has demonstrated that stressors such as climate change, eutrophication or urbanisation strongly affect marine canopies (e.g. Mangialajo et al., 2008). However, both direct and indirect human-induced modifications on physical habitat, acting as drivers for the decline of canopy-forming algae, have been usually overlooked (Perkol-Finkel and Airoldi, 2010).

Many coasts are becoming increasingly urbanised worldwide. This coastal urbanisation can result in extensive modification of natural shores, altering habitat heterogeneity, complexity, slope and available area for benthic biota. This affects natural processes e.g. recruitment, colonization, survival, population densities and connectivity, fecundity or/and species interaction (Bulleri et al., 2004; Bulleri, 2005; Chapman and Bulleri, 2003; Moreira et al., 2006; Perkol-Finkel and Airoldi, 2010). Several studies have investigated the patterns of distribution of benthic communities supported by artificial coastal defence structures and showed they are generally poor surrogates for the habitats they replace (e.g. Moschella et al., 2005). Although a variety of factors differ between artificial structures and the adjacent rocky shores, substratum slope is often fundamentally different. This modified slope has been shown to be a major determinant influencing the structure of intertidal assemblages (Bulleri and Chapman, 2004; Glasby and Connell, 2001). The differences in assemblages generated and maintained by a combination of differential recruitment and post-recruitment processes (Vaselli et al., 2008), result in considerable changes to coastal ecology. Canopy-forming algae are strongly affected by urbanisation (Airoldi and Beck, 2007; Benedetti-Cecchi et al., 2001), and little is known about the consequences of changes in the habitat related characteristics of the shore for their functional properties, like productivity and resilience (i.e. the ability of organisms to recover after events of disturbance, Grimm and Wissel, 1997). Changes have already been 
74 showed in demographic parameters such as growth or mortality of populations submitted

75 to disturbance (Araújo et al., 2011), or in morphological parameters such as thalli

76 thickness against desiccation stress or thalli size against wave exposure (Blanchette, 1997;

77 Jorve, 2008). The steep slope of artificial structures could alter the physical stress to which

78 plants are submitted, e.g. different desiccation regimes, and therefore change life-history

79 traits, namely differentiation of populations via phenotypic plasticity (Blanchette, 1997).

80 Moreover, although dispersal via drifting algal rafts has been cited as a mechanism to

81 increase its gene flow (Coleman and Brawley, 2005), gamete dispersal is limited in fucoids

82 (Coyer et al., 2011). This can limit its ability to colonise the "newer" habitats.

83 Understanding the processes that maintain differences in canopy-forming algae

84 recruitment, growth and survival among different substrata, and identifying the factors that

85 promote the loss of canopy-forming species, is thus of great importance in order to evaluate the consequences of coastal urbanisation worldwide and effectively manage and preserve marine coastlines (Coleman et al., 2008; Perkol-Finkel et al., 2012). But although potential explanations have been suggested, experimental tests of causal effects are not common and have usually focused on artificial substrata (Glasby, 2000).

In the Northeast Atlantic midshore there is generally a dynamic balance between fucoids,

91 barnacles and limpets on the shore (Hawkins and Hartnoll, 1983; Hawkins et al., 1992;

92 Thompson et al., 1996), although fucoids become less predominant at lower latitudes

93 (Ballantine, 1961). The upper eulittoral in the Azores oceanic archipelago (located between $37-40^{\circ} \mathrm{N}$ and $25-31^{\circ} \mathrm{W}$ ) is often dominated by two perennial macroalgae species, the Ochrophyta Fucus spiralis Linnaeus and the Rodophyta Gelidium microdon Kützing, 1849. The desiccation-resistant $F$. spiralis is the unique species of the genus found in

97 Azores, where it forms scattered populations. It appears on exposed shores, in areas that are partially sheltered and not directly exposed to the full force of the incoming waves 
99 (Neto, 2000), and although it can appear on a variety of slopes, their abundance generally 100 increase with decreasing slope (pers. observ). In Azorean coasts, formed by steep cliffs 101 and volcanic rubbles, most artificial structures are used to protect nearby towns from high 102 sea levels during winter storms. Coastal defences are mostly built by deploying piles of 103 locally quarried rock or concrete boulders upon natural rocky shores, resulting in artificial 104 structures with steeper inclination than natural shores. Although epibenthic assemblage 105 composition differ (Cacabelos et al., in press), qualitative similarities were found on both 106 natural habitats and coastal defences. However, F. spiralis is conspicuously absent from 107 these coastal defences, even though it can occur in the adjacent rocky intertidal.

108 Here we investigate factors that could potentially limit the ability of $F$. spiralis from 109 establishing onto artificial structures. Specifically, we investigate the effects of substratum 110 slope (vertical vs horizontal) on the growth and the level of desiccation of adult $F$. spiralis, 111 and on the survival of recruits. In addition, we measured recruitment at several distances

112 from the nearest source of propagules (clumps of $F$. spiralis) to investigate the species 113 ability to disperse and colonise new areas.

\section{2. Material and Methods}

115 We tested the hypothesis that $F$. spiralis is absent from artificial structures because adult 116 plants do not survive on vertical or nearly vertical slopes. Adult individuals were collected

117 in the field from horizontal substrates and plants. They were weighed (fully hydrated wet 118 weight, WW) and the fronds length (L) and maximum circumference (perimeter, $\mathrm{P}$ ) 119 measured. Dichotomies and receptacles were counted. Plants were then attached to nets 120 that were subsequently attached to the substratum using stainless screws. Experimental 121 plants were placed following the same procedure in interspersed areas with nearly 122 horizontal and nearly vertical surfaces in the natural shore. Plants transplanted to 123 horizontal surfaces were used to control the effects of manipulation (procedural control). 
124 The entire procedure was accomplished in situ and as quickly as possible to minimize the 125 disturbance effect of the manipulation. Unmanipulated individuals (on horizontal surfaces) 126 were randomly selected and marked to be measured as above and used as controls $(n=$ 127 6). For these, WW was estimated indirectly using WW-LC ${ }^{2}$ regressions (Åberg, 1990).

128 The experiment was initiated at the end of July 2014 and replicated on two natural shores 129 of similar wave exposure (site 1, Farol; site 2, Vulcanológico). After 3 months plants were 130 re-measured and re-weighed, and linear growth, variations in biomass and number of 131 dichotomies and receptacles were calculated by subtracting the initial values to the final 132 ones.

133 The effect of slope on desiccation was investigated by comparing loss of water from plants $134(n=6)$ deployed on horizontal and vertical surfaces in mesocosm. Tissue weight $(\mathrm{Wt})$ was 135 recorded for each plant every hour for a period of 5 hours, and finally, plants were dried at $13660^{\circ} \mathrm{C}$ for $48 \mathrm{~h}$ to estimate the dry weight (DW). The relative water content (RWC) of each 137 plant was calculated according to the formula RWC $=(\mathrm{Wt}-\mathrm{DW}) /(\mathrm{WW}-\mathrm{DW})(\mathrm{DW}$, dry 138 weight; Shafer et al. 2007). RWC of each plant was plotted against elapsed time, and 139 exponential curves were fitted to each plot by using the formula $I_{t}=I_{0} e^{-k t}\left(I_{t}, R W C\right.$ at time $t$; $140 \mathrm{I}_{0}, \mathrm{RWC}$ at initial time; k, desiccation coefficient; Tanaka and Nakaoka, 2004).

141 To test the hypothesis that surface slope affects the early survivorship of recently recruited 142 plants, fertile receptacles of $F$. spiralis were collected from the field early April 2015 to be 143 used as source of zygotes. Receptacles were taken to the laboratory inside plastic bags in 144 an ice-chest and kept in darkness. Receptacles were then washed in cold seawater, wiped 145 with paper towels and placed on dry tissue paper at room temperature for zygotes release, 146 following the protocol of McLachlan et al. (1971). The partially dehydrated receptacles 147 were then placed inside dry grass covered Petri dishes and kept inside a culture chamber 148 at $8^{\circ} \mathrm{C}$ in the dark overnight. When zygotes started to release, receptacles were covered 
149 with cold sterile seawater until zygotes complete release and sunk to the bottom of the 150 dish. Zygotes were then isolated from conspicuous mucilage, translated to aquaria with 151 sterile seawater where the bottom was covered with recruitment plates $(6 \times 6 \mathrm{~cm})$, and 152 allowed to settle. Plates were incubated at room temperature, changing half of the water 153 every 3 days. After 10 days, the initial concentration of recruits in plates was counted in 6 154 fixed sub-quadrats $1.5 \times 1.5 \mathrm{~cm}$ under binocular lens. Plates were then transported to the 155 field and randomly attached onto horizontal and vertical surfaces $(n=8)$ using stainless 156 screws. After a period of $24 \mathrm{~h}$, plates were retrieved, carefully brought to the laboratory 157 where recruits density was estimated as described above. Percentage survivorship of 158 recruits was calculated as $N_{f} / N_{0} * 100$, where $N_{f}$ is the average number of surviving 159 settlers per plate at $24 \mathrm{~h}$, and $\mathrm{N}_{0}$ is the number of settled recruits at the initial moment.

160 We further investigated if substratum slope influences local hydrodynamic conditions by 161 deploying pre-weighted plaster discs attached to the substratum in horizontal and vertical 162 areas of the shore ( $\mathrm{n}=5$ per treatment). Discs were retrieved $48 \mathrm{~h}$ and one week later, 163 dried until constant weight was obtained and re-weighted to calculate weigh loss.

164 To test the hypothesis that the absence of $F$. spiralis on artificial structures is due to a 165 limitation of a source of propagules for colonisation we investigated recruitment rates at 166 increasing distances from clumps of mature plants. Recruitment plates $(n=5) 6 \times 6 \mathrm{~cm}$ 167 were deployed in the field at three increasing distances from adults: $0 \mathrm{~cm}$ (i.e., under the 168 frond), $10 \mathrm{~cm}$ and $>0.5 \mathrm{~m}$. After 75 days, plates were collected and carefully brought to 169 the laboratory where the number of recruits was counted on each plate under binocular 170 lens in four sub-quadrats $\left(3.25 \mathrm{~cm}^{2}\right)$ per plate.

$171 \quad 2.1$ Data analysis 
172 A two-way mixed model analysis of variance (ANOVA) was used to compare linear growth,

173 variations in biomass, numbers of dichotomies and receptacles among sites (Si, random

174 factor, 2 levels) and treatments (Tr, fixed factor, 3 levels: Horizontal (procedural control),

175 Vertical, Control). Student-Newman-tests (SNK) were used to compare means within

176 significant terms. In order to examine initial differences among plants assigned to each

177 treatment, linear length, biomass, and numbers of dichotomies and receptacles measured

178 before manipulations were compared using ANOVA, with the same model described

179 above. A one-way ANOVA was used to compare the desiccation coefficients of adult

180 plants, recruit survivorship and weight loss of plaster discs between slopes (Or, fixed factor,

1812 levels: Horizontal, Vertical). A two-way ANOVA was also used to compare the

182 recruitment rates among plates ( $\mathrm{PI}$, random factor) at increasing distances (Dist, fixed

183 factor, 3 levels: $0 \mathrm{~cm}, 10 \mathrm{~cm},>0.5 \mathrm{~m}$ ). Prior to analyses, Cochran's tests were used to

184 detect heterogeneity of variances and data were transformed where appropriate

185 (Underwood, 1997). When homogeneity of data was not achieved after transformation, 186 analyses were run on the untransformed data but using a more conservative significance 187 level $(\alpha<0.01)$ (Underwood, 1997).

188 3. Results

189 Comparisons among plants before experimental manipulations

190 ANOVA did not detect any significant differences among the measures of the plants

191 allocated to each treatment at the beginning of the study (Table 1).

192 Effect of substratum slope.

193 Significant variation was found in the length and number of dichotomies of Fucus spiralis

194 between treatments (Table 2). SNK tests showed that the length of $F$. spiralis transplanted

195 to vertical surfaces differed significantly from both plants transplanted to horizontal 
196

197

surfaces and unmanipulated controls, while no significant difference was found between the last two treatments (Table 2). F. spiralis transplanted to vertical surfaces suffered a reduction in length (Fig. 1, mean \pm SE; site 1: $-1.2 \pm 1.1 \mathrm{~cm}$, site 2: $-3.7 \pm 0.9 \mathrm{~cm}$ ), whilst plants transplanted to horizontal surfaces as well as controls grew similar lengths (site 1: $2.3 \pm 0.3$, site $2: 0.0 \pm 0.9 \mathrm{~cm}$ ). Similarly, the number of dichotomies was also significantly lower, and showed on average a $6.8 \pm 3.3$ reduction compared to original numbers) in plants transplanted to vertical surfaces, whereas similar numbers of dichotomies were found in plants transplanted to horizontal surfaces and controls and there were on average $11.0 \pm 3.7$ more dichotomies since the start of the experiment (Fig. 1, Table 2). Even though $F$. spiralis wet weight and number of receptacles tended to increase in both controls and plants transplanted to horizontal surfaces (especially on site 1), there was no significant difference among treatments (Fig. 1, Table 2) as there was large variability among individuals. There were also no differences on desiccation coefficients of adult plants deployed on horizontal and vertical surfaces (Fig. 2, Table 3).

After $24 \mathrm{~h}$, the survivorship of recruits deployed on horizontal and vertical surfaces was similar, as was the mean weight loss of plaster discs across time (Fig. 3, Table 3).

Ability of Fucus spiralis to disperse away from source plants. Mean density of recruits on plates deployed at different distances from source clumps of $F$. spiralis differed markedly. While mean densities of up to 18 ind. $\mathrm{cm}^{2}$ were observed under the canopy, fail recruitments were observed at $10 \mathrm{~cm}$ and $0.5 \mathrm{~m}$ away from F. spiralis clumps (Fig. 4, Table 4).

\section{Discussion}

There were negative effects of vertical slope on the development of adult Fucus spiralis. Lower linear growth and increment in number of dichotomies on adults were observed on 
220

221

222

223

224

225

226

227

228

229

230

231

232

233

234

235

236

237

238

239

240

241

242

243

244

vertical surfaces, suggesting that the different conditions were determinant for $F$. spiralis populations. We expected differences would rely on hydrodynamic forces or desiccation regimes to which plants are submitted. In fact, several studies concluded that wave force was the dominant controlling factor affecting Fucus spp. and other canopy-forming algae (Jonsson et al., 2006; Moschella et al., 2005; Perkol-Finkel et al., 2012), limiting their survival through mechanical abrasion, dislodging or pruning. However, no differences were found in the hydrodynamic regime among vertical and horizontal slopes (plaster discs), nor on desiccation levels. This suggests that other physical and/or biological factors could be involved in shaping F. spiralis populations, as mentioned by Thompson et al. (2004) for algal biofilm. For example, grazers such as amphipods, limpets, periwinkle $T$. striatus, or fishes such as Salpa salpa, usually present in the studied intertidal level, were not excluded in our experimental study, and their effect on macroalgae may be among possible relevant causes for obtained patterns. Previous studies showed grazing was sufficient to prevent the establishment of macroalgae, being important determinants for either adult or post-settler stages (Chapman, 1989; Creese, 1988; Jenkins et al., 2005 and references therein). Besides variations in grazing and predation activity, changes in geomorphology or whiplash by seaweed itself (see Chappuis et al. 2014), together with wave exposure, barnacle presence or microtopography have been cited as other important factors in determining the abundance of Fucus spp. at either juvenile or adult stages (Chapman, 1989; Lamote and Jonhnson, 2008; Moschella et al., 2005). Findings for other canopy-forming algae, Cystoseira, suggested that both the availability and the stability of substrata, as well as biotic disturbances (both consumptive and non-consumptive interactions), proved to be key determinants in limiting their abundance (Ferrario et al., 2015; Perkol-Finkel and Airoldi, 2010). Therefore, these and other potential physical and/or biological factors should be evaluated in further studies to determine their role in 
245 shaping F. spiralis populations, e.g. when managing assemblages on newly built man246 made structures.

247 Our results on the recruitment patterns strongly contrast with those of Chapman (1989), 248 who found the intraspecific suppression of $F$. spiralis recruits by adult canopy. In our case, 249 the analysis of natural recruitment patterns on bedrocks showed that the most important 250 regulator of recruitment density was the presence of a canopy of conspecific adults, 251 whereas transplanted recruits did not show different survival patterns related to substratum 252 slope. Contrastingly, negative effect of increased slope (i.e. vertical) was evident from 253 transplantation experiments of adults. Reduced density of canopy-forming algae has been 254 already observed in urbanised coasts (e.g. in the Mediterranean, Benedetti-Cecchi et al., 255 2001; in Sydney, Coleman et al., 2008). Responses obtained in this study, together with 256 the lack of surrounding adult fronds on Azorean artificial structures, and the fact that 257 distance from canopy greatly reduced juvenile recruitment, is sufficient to explain the 258 absence of canopies on these coastal defences. This knowledge could aid programmes of 259 restoration or rehabilitation of damaged habitats and contribute to the ecological criteria 260 that should be considered in the design and management of artificial structures.

261 Conservation, planning and policy targets for biodiversity enhancement could be 262 supported by establishment and recovery of canopy-forming species on rocks and 263 engineered structures (Coombes et al., 2013). Understanding how characteristics of 264 shores alter the structure and functioning of canopy-forming algae should be relevant 265 information to be used for conservation purposes, namely in definition of criteria to be 266 integrated into the design and construction of future urban structures (Coombes et al., 267 2013; Perkol-Finkel et al., 2012). This information would minimise ecological impacts or 268 artificial structures, allowing targeted management of diversity and natural living resources. 269 Many habitat restoration efforts are concentrated on preservation of biodiversity, as well as 
270 of the critical socioeconomic resources provided by many natural habitats, such as

271 canopies (Perkol-Finkel and Airoldi, 2010). Increase the supply of canopy-forming

272 propagules to artificial structures, turfs removal for extending the area over which canopies

273 can maintain free substratum for recruitment, or active canopy transplantation has been

274 proposed as means of aiding the restoration of forested landscapes and facilitating the

275 recovery of large gaps (Emmerson and Collings, 1998; Gorman and Connell, 2009; Irving

276 and Connell, 2006; Mangialajo et al., 2008). Although potential recovery measures have

277 been globally suggested in the literature, management requires approaches that focus on

278 local scales (Strain et al., 2015). Therefore understanding how local characteristics

279 modulate the structure and functioning of canopies should be information to be considered

280 for conservation purposes. Our study reinforces the notion that a greater proportion of

281 vertical surfaces compared to natural habitats, consequence of urbanisation, could

282 strongly affect Azorean canopy-forming algae. Assisted introductions for other canopy-

283 forming algae have been suggested as potential strategies for management of coastal

284 defences (Perkol-Finkel et al., 2012). Although we observed a high recruitment rate under

285 adult plants and successful survival rates for transplanted recruits, the negative effects

286 observed on adult growth do not insure assisted introductions as a promising measure to

287 facilitate the colonization of coastal defences. Climate-driven threats (e.g. increased

288 storminess, adding instability) could also play an important role in regulating the loss of

289 marine canopies, limiting their adaptive capacity to future scenarios (Perkol-Finkel and

290 Airoldi, 2010). These could have important effects on Azorean coasts, where F. spiralis is

291 the only leathery canopy-forming algae at upper intertidal level (Neto, 2000) ameliorating

292 the otherwise harsh conditions during low tides (Watt and Scrosati, 2014).

293 Acknowledgements 
294 Authors are grateful to Virginie Leyendecker, Mónica Martínez, Rubén Mosquera, Enrique

295 Almira, Eduardo García and Ane Laborda for field and laboratory assistance. This

296 research was partially supported by the European Regional Development Fund (ERDF)

297 through the COMPETE - Operational Competitiveness Programme and national funds

298 through FCT - Foundation for Science and Technology, under the project "PEst-

299 C/MAR/LA0015/2013, by the Strategic Funding UID/Multi/04423/2013 through national

300 funds provided by FCT and European Regional Development Fund (ERDF) in the

301 framework of the programme PT2020, and by cE3c funding (Ref: UID/BIA/00329/2013).

302 GMM was supported by a postdoctoral grant awarded by FCT (SFRH/BDP/63040/2009).

303 ACLP was funded by a FRCT research grant M3.1.5/F/098/2012. Support was also

304 provided by CIRN/UAc (Centre of Natural Resources of University of the Azores).

\section{References}

Åberg, P., 1990. Measuring size and choosing category size for a transition matrix study of 309 the seaweed Ascophyllum nodosum. Mar. Ecol. Prog. Ser. 63, 281-287.

310 Airoldi, L., Beck, M.W., 2007. Loss, status and trends for coastal marine habitats of Europe.

311 Oceanogr. Mar. Biol. Annu. Rev. 45: 345-405.

312 Araújo, R., Serrão, E., Sousa-Pinto, I., Åberg, P., 2011. Phenotypic differentiation at

313 southern limit borders: the case study of two fucoid macroalgal species with different life-

314 history traits. J. Phycol. 47, 451-462.

315 Ballantine, W.J., 1961. A biologically defined exposure scale for the comparative 316 description of rocky shores. Field Stud 1, 1-19. 
317 Benedetti-Cecchi, L., Pannacciulli, F., Bulleri, F., Moschella, P.S., Airoldi, L., Relini, G., 318 Cinelli, F., 2001. Predicting the consequences of anthropogenic disturbance: large-scale 319 effects of loss of canopy algae on rocky shores. Mar. Ecol. Prog. Ser. 214, 137-150.

320 Bertocci, I., Araújo, R., Vaselli, S., Sousa-Pinto, I., 2011. Marginal populations under 321 pressure: spatial and temporal heterogeneity of Ascophyllum nodosum and associated 322 assemblages affected by human trampling in Portugal. Mar. Ecol. Prog. Ser., 439: 73-82.

323 Blanchette, C.A., 1997. Size and survival of intertidal plants in response to wave action: A 324 case study with Fucus gardneri. Ecology 78(5), 1563-1578.

325 Bulleri, F., 2005. Role of recruitment in causing differences between intertidal 326 assemblages on seawalls and rocky shores. Mar. Ecol. Prog. Ser. 287, 53-65.

327 Bulleri, F., Chapman, M.G., 2004. Intertidal assemblages on artificial and natural habitats 328 in marinas on the north-west coast of Italy. Mar. Biol. 145, 381-391.

329 Bulleri, F., Chapman, M.G., Underwood, A.J., 2004. Patterns of movement of the limpet 330 Cellana tramoserica on rocky shores and retaining seawalls. Mar. Ecol. Prog. Ser. 281, $331 \quad 121-129$.

332 Cacabelos, E., Martins, G.M., Thompson, R.C., Prestes, A.C.L., Azevedo, J.M.N., Neto, 333 A.I. (in press) Material type and roughness influence structure of intertidal communities on 334 coastal defences. Mar. Ecol.

335 Chapman, A.R.O., 1989. Abundance of Fucus spiralis and ephemeral seaweeds in a high 336 eulittoral zone: effects of grazers, canopy and substratum type. Mar. Biol. 102, 565-572.

337 Chapman, M.G., Bulleri, F., 2003. Intertidal seawalls-new features of landscape in 338 intertidal environments. Landscape Urban Plann. 62(3), 159-172. 
339 Chappuis, E., Terradas , M., Cefalì, M.E., Marinai, S., Ballesteros. E., 2014. Vertical

340 zonation is the main distribution pattern of littoral assemblages on rocky shores at a

341 regional scale. Estuar., Coast. Shelf Sci. 147, 113-122.

342 Coleman, M.A., Kelaher, B.P., Steinberg, P.D., Millar, A.J.K., 2008. Absence of a large

343 brown macroalga on urbanized rocky reefs around Sydney, Australia, and evidence for

344 historical decline. J. Phycol. 44(4), 897-901.

345 Coleman, M.A., Brawley, S.H., 2005. Are life history characteristics good predictors of

346 genetic diversity and structure? A case study of the intertidal alga Fucus spiralis

347 (Heterokontophyta; Phaeophyceae). J. Phycol. 41, 753-762.

348 Coombes, M.A., Naylor, L.A., Viles, H.A., Thompsn, R.C., 2013. Bioprotection and

349 disturbance: seaweed, microclimatic stability and conditions for mechanical weathering in

350 the intertidal zone. Geomorphology 202, 4-14.

351 Coyer, J.A., Hoarau, G., Costa, J.F., Hogerdijk, B., Serrão, E.A., Billard, E., Valero, M.,

352 Pearson, G.A., Olsen, J.L., 2011. Evolution and diversification within the intertidal brown

353 macroalgae Fucus spiralis/F. vesiculosus species complex in the North Atlantic. Mol.

354 Phylogenet. Evol. 58(2), 283-296.

355 Creese, R.G., 1988. Ecology of molluscan grazers and their interactions with marine algae

356 in north-eastern New Zealand: a review. N. Z. J. Mar Freshwater Res. 22, 427-444.

357 Davison, I.R., Pearson, G.A., 1996. Stress tolerance in intertidal seaweeds. J. Phycol. 32, $358 \quad 197-211$.

359 Emmerson, L.M., Collings, G.J., 1998. Macroalgal recruitment in artificially disturbed areas:

360 interactive effects of temporal and spatial scale. Mar. Freshwater Res. 49, 541-546. 
361 Ferrario, F., Iveša, L., Jaklin, A., Perkol-Finkel, S., Airoldi, L., 2015. The overlooked role of

362 biotic factors in controlling the ecological performance of artificial marine habitats. J. Appl.

363 Ecol. DOI: 10.1111/1365-2664.12533.

364 Glasby, T.M., 2000. Surface composition and orientation inter-act to affect subtidal

365 epibiota. J. Exp. Mar. Biol. Ecol. 248, 177-190.

366 Glasby, T.M., Connell, S.D., 2001. Orientation and position of substrata have large effects 367 on epibiotic assemblages. Mar. Ecol. Prog. Ser. 214, 127-135.

368 Gorman, D., Connell, S.D., 2009. Recovering subtidal forests in human-dominated 369 landscapes. J. Appl. Ecol. 46, 1258-1265.

370 Grimm, V., Wissel, C., 1997. Babel, or the ecological stability discussions: an inventory 371 and analysis of terminology and a guide for avoiding confusion. Oecologia 109, 323-334.

372 Hawkins, S.J., Hartnoll, R.G., 1983. Grazing of intertidal algae by marine invertebrates.

373 Oceanogr. Mar. Biol. Annu. Rev. 21, 195-282.

374 Hawkins, S.J., Hartnoll, R.G., Kain, J.M., Norton, T.A., 1992. Plant animal interactions on 375 hard substrata in the North-east Atlantic, in: John DM, Hawkins SJ, Price JH (Eds) Plant 376 animal interactions in the marine benthos. Systematics Association Spec Vol 46.

377 Clarendon Press, Oxford, pp. 1-32.

378 Irving, A.D., Connell, S.D., 2006. Predicting understorey structure from the presence and 379 composition of canopies: an assembly rule for marine algae. Oecologia 148, 491-502.

380 Jenkins, S.R., Coleman, R.A., Della Santina, P., Hawkins, S.J., Burrows, M.T., Hartnoll, 381 R.G., 2005. Regional scale differences in the determinism of grazing effects in the rocky 382 intertidal. Mar. Ecol. Prog. Ser. 287, 77-86. 
383 Jonsson PR, Granhag L, Moschella PS, Aberg P, Hawkins SJ, Thompson RC., 2006.

384 Interactions between wave action and grazing control the distribution of intertidal 385 macroalgae. Ecology 87(5), 1169-1178.

386 Jorve, J.P., 2008. Ecological consequences of morphological variability in a habitat387 forming alga. Master's Theses. San Jose State University, California, 133 pp.

388 Lamote, M., Johnson, L.E., 2008. Temporal and spatial variation in the early recruitment of 389 fucoid algae: the role of microhabitats and temporal scales. Mar. Ecol. Prog. Ser. 368, 93390102.

391 Mangialajo, L., Chiantore, M., Cattaneo-Vietti, R., 2008. Loss of fucoid algae along a 392 gradient of urbanisation, and structure of benthic assemblages. Mar. Ecol. Prog. Ser. 358, $393 \quad 63-74$.

394 Martinez, B., Viejo, R.M., Carreño, F., Aranda, S.C., 2012. Habitat distribution models for 395 intertidal seaweeds: responses to climatic and non-climatic drivers. J. Biogeogr. 39, 18773961890.

397 McLachlan, J., Chen, L.C.-M., Edelstein, T., 1971. The culture of four species of Fucus 398 under laboratory conditions. Can. J. Bot. 49, 1463-9.

399 Moreira J., Chapman M.G., Underwood A.J., 2006. Seawalls do not sustain viable 400 populations of limpets. Mar. Ecol. Prog. Ser. 322, 179-188.

401 Moschella P.S., Abbiati M., Aberg P., Airoldi L., Anderson J.M., Bacchiocchi F., Bulleri F., 402 Dinesen G.E., Frost M., Gacia E., Granhag L., Johnson P.R., Satta M.P., Sundelõf A., 403 Thompson R.C., Hawkins S.J., 2005. Low-crested coastal defence structures as artificial 404 habitats for marine life: using ecological criteria in design. Coastal Eng. 52, 1053-1071. 
405 Neto, A.I., 2000. Ecology and dynamics of two intertidal algal communities on the littoral of 406 the island of São Miguel (Azores). Hydrobiologia 432, 135-147.

407 Perkol-Finkel, S., Airoldi, L., 2010. Loss and recovery potential of marine habitats: an 408 experimental study of factors maintaining resilience in subtidal algal forests at the Adriatic 409 Sea. PLoS ONE 5(5): e10791. doi:10.1371/journal.pone.0010791

410 Perkol-Finkel, S., Ferrario, F., Nicotera V., Airoldi, L., 2012. Conservation challenges in 411 urban seascapes: promoting the growth of threatened species on coastal infrastructures. J. 412 Appl. Ecol. 49, 1457-1466.

413 Shafer, D.J., Sherman, T.D., Wyllie-Echeverria, S. 2007. Do desiccation tolerances control 414 the vertical distribution of intertidal seagrasses?. Aquat. Bot. 87, 161-166.

415 Smale, D.A., Burrows, M.T., Moore, P., O'Connor, N., Hawkins, S.J., 2013.Threats and 416 knowledge gaps for ecosystem services provided by kelp forests: a northeast Atlantic 417 perspective. Ecol. Evol. 3(11), 4016-4038.

418 Strain, E.M.A., van Belzen, J., van Dalen, J., Bouma, T.J., Airoldi, L., 2015. Management 419 of local stressors can improve the resilience of marine canopy algae to global stressors. 420 PLoS ONE 10(3): e0120837. doi:10.1371/journal.pone.0120837

421 Tanaka, Y., Nakaoka, M., 2004. Emergence stress and morphological constraints affect 422 the species distribution and growth of subtropical intertidal seagrasses. Mar. Ecol. Prog. 423 Ser. 284, 117-131.

424 Thompson R.C., Wilson B.J., Tobin M.L., Hill A.S., Hawkins S.J., 1996. Biologically 425 generated habitat provision and diversity of rocky shore organisms at a hierarchy of spatial 426 scales. J. Exp. Mar. Biol. Ecol. 202, 73-84. 
427 Thompson, R.C., Norton, T.A., Hawkins, S.J., 2004. Physical stress and biological control

428 regulate the producer-consumer balance in intertidal biofilms. Ecology 85, 1372-1382.

429 Underwood, A.J., 1997. Experiments in ecology: their logical design and interpretation

430 using analysis of variance. Cambridge University Press, Cambridge.

431 Vaselli, S., Bertocci, I., Maggi, E., Benedetti-Cecchi, L., 2008. Assessing the

432 consequences of sea level rise: effects of changes in the slope of the substratum on

433 sessile assemblages of rocky seashores. Mar. Ecol. Prog. Ser. 368, 9-22.

434 Voerman, S.E., Llera, E., Rico, J.M., 2013. Climate driven changes in subtidal kelp forest

435 communities in NW Spain. Mar. Environ. Res. 90, 119-127.

436 Watt, C.A., Scrosati, R.A., 2014. Experimental and mensurative data on the abundance of 437 primary producers and consumers from intertidal habitats in Canada. Ecology 95, 1429_ 4381429. 
Tables

449 Table 1. ANOVA testing for differences on F. spiralis linear length and numbers of

450 dichotomies and receptacles and in wet weight at different sites and treatments $(\mathrm{H}$

451 Horizontal, V Vertical, C Control) $(n=6) .{ }^{*} P<0.05,{ }^{n s}$ no significant.

\begin{tabular}{|c|c|c|c|c|c|c|c|c|c|}
\hline \multirow[b]{2}{*}{ Source } & \multirow[b]{2}{*}{ df } & \multicolumn{2}{|c|}{ Linear length } & \multicolumn{2}{|c|}{$\mathrm{N}$ dichotomies } & \multicolumn{2}{|c|}{$\mathrm{N}$ receptacles } & \multicolumn{2}{|l|}{ WW } \\
\hline & & MS & $\mathrm{F}$ & MS & $\mathrm{F}$ & MS & $\mathrm{F}$ & MS & $\mathrm{F}$ \\
\hline Site $(=S i)$ & 1 & 9.56 & $3.41^{\mathrm{ns}}$ & 11.11 & $0.14^{\mathrm{ns}}$ & 17.36 & $5.06^{*}$ & 0.29 & $0.93^{\mathrm{ns}}$ \\
\hline Treatment $(=\mathrm{Tr})$ & 2 & 3.92 & $1.40^{\mathrm{ns}}$ & 6.08 & $0.08^{\mathrm{ns}}$ & 1.36 & $0.40^{\mathrm{ns}}$ & 0.10 & $0.32^{\mathrm{ns}}$ \\
\hline $\mathrm{Si} \times \mathrm{Tr}$ & 2 & 1.80 & $0.64^{\mathrm{ns}}$ & 37.53 & $0.49^{n s}$ & 1.36 & $0.40^{\mathrm{ns}}$ & 0.04 & $0.12^{n s}$ \\
\hline Res & 30 & 2.81 & & 76.99 & & 3.42 & & 0.31 & \\
\hline Total & 35 & & & & & & & & \\
\hline \multicolumn{10}{|l|}{ SNK } \\
\hline Cochran's test & & $0.2411^{\mathrm{ns}}$ & & $0.2812^{\mathrm{ns}}$ & & 0.6110 & & 0.36 & \\
\hline Transformation & & None & & None & & None & & None & \\
\hline
\end{tabular}

452

453

454

455

456

457 
458 Table 2. ANOVA testing for the effects of site and treatment (H Horizontal, V Vertical, C 459 Control) on F. spiralis linear growth and variation numbers of dichotomies and receptacles 460 and in wet weight $(\mathrm{n}=6) .{ }^{* *} P<0.01,{ }^{*} P<0.05,{ }^{\text {ns }}$ no significant.

\begin{tabular}{|c|c|c|c|c|c|c|c|c|c|}
\hline \multirow[b]{2}{*}{ Source } & \multirow[b]{2}{*}{$\mathrm{df}$} & \multicolumn{2}{|c|}{ Linear growth } & \multicolumn{2}{|c|}{$\mathrm{N}$ dichotomies } & \multicolumn{2}{|c|}{$\mathrm{N}$ receptacles } & \multicolumn{2}{|l|}{ WW } \\
\hline & & MS & $\mathrm{F}$ & MS & $\mathrm{F}$ & MS & $F$ & MS & $F$ \\
\hline Site $(=S i)$ & 1 & 41.11 & $6.90^{*}$ & 448.03 & $1.75^{\mathrm{ns}}$ & 462.25 & $6.45^{*}$ & 8.64 & $0.60^{n s}$ \\
\hline Treatment $(=\mathrm{Tr})$ & 2 & 50.66 & $8.50^{* *}$ & 1384.02 & $5.42^{* *}$ & 103.86 & $1.45^{\mathrm{ns}}$ & 45.01 & $3.15^{\mathrm{ns}}$ \\
\hline $\mathrm{Si} \times \mathrm{Tr}$ & 2 & 3.59 & $0.60^{\mathrm{ns}}$ & 105.86 & $0.41^{\mathrm{ns}}$ & 18.58 & $0.26^{\mathrm{ns}}$ & 12.36 & $0.87^{\mathrm{ns}}$ \\
\hline Res & 30 & 5.96 & & 255.33 & & 71.68 & & 14.29 & \\
\hline \multirow[t]{2}{*}{ Total } & 35 & & & & & & & & \\
\hline & & $\mathrm{H}$ diff $\mathrm{V}^{* *}$ & & $\mathrm{H}$ diff $\mathrm{V}^{*}$ & & & & & \\
\hline \multirow[t]{2}{*}{ SNK } & & $V \operatorname{diff} C^{* *}$ & & $V \operatorname{diff} C^{* *}$ & & & & & \\
\hline & & $\mathrm{C}=\mathrm{H}$ & & $\mathrm{C}=\mathrm{H}$ & & & & & \\
\hline Cochran's test & & $0.5071^{*}$ & & $0.4543^{*}$ & & $0.8070^{* *}$ & & 0.4718 & \\
\hline Transformation & & None & & None & & None & & None & \\
\hline
\end{tabular}

461

462

463

464

465

466 
467 Table 3. ANOVA testing for the effects of slope on desiccation coefficient of $F$. spiralis

468 adults $(n=6)$, and on survivorship of recruits $(n=8)$, and weight loss $(W L)$ of plaster discs

$469(\mathrm{n}=5)$ after different time periods. ${ }^{* *} P<0.01,{ }^{*} P<0.05,{ }^{\text {ns }}$ no significant

\begin{tabular}{|c|c|c|c|c|c|c|c|c|c|c|c|}
\hline \multirow[b]{2}{*}{ Source } & \multirow[b]{2}{*}{ df } & \multicolumn{2}{|c|}{$\begin{array}{l}\text { Desiccation } \\
\text { coefficient }\end{array}$} & \multicolumn{3}{|c|}{$\begin{array}{l}\text { Survivorship } \\
(24 \mathrm{~h})\end{array}$} & \multicolumn{2}{|c|}{ WL(48h) } & \multicolumn{3}{|c|}{ WL(1week) } \\
\hline & & MS & $\mathrm{F}$ & df & MS & $\mathrm{F}$ & df & MS & $\mathrm{F}$ & MS & $\mathrm{F}$ \\
\hline Slope & 1 & 0.0021 & $3.21^{\mathrm{ns}}$ & 1 & 507.38 & $1.05^{\text {ns }}$ & 1 & 651.73 & $2.50^{\mathrm{ns}}$ & 627.74 & $3.23^{\mathrm{ns}}$ \\
\hline Res & 10 & 0.0007 & & & 482.97 & & 8 & 260.34 & & 194.59 & \\
\hline Total & 11 & & & 15 & & & 9 & & & & \\
\hline Cochran's test & & $0.8105^{\text {ns }}$ & & & $0.5193^{\text {ns }}$ & & & $0.9114^{*}$ & & $0.9407^{*}$ & \\
\hline Transformation & & $x^{\wedge} 3$ & & & None & & & None & & None & \\
\hline
\end{tabular}

470

471

472

473

474

475

476

477

478

479 
480 Table 4. ANOVA testing for the effects of distance $(0 \mathrm{~cm}, 10 \mathrm{~cm},>0.5 \mathrm{~m})$ and plate on $F$. 481 spiralis recruitment $(\mathrm{n}=4) .{ }^{* *} P<0.01$.

\begin{tabular}{lccc} 
& \multicolumn{3}{l}{ Recruitment } \\
\hline Source & df & MS & $\mathrm{F}$ \\
\hline Distance (D) & 2 & 19910.8 & $9.21^{\text {** }}$ \\
Plate (=PI) & 4 & 2160.9 & $1.56^{\mathrm{ns}}$ \\
Dist x PI & 8 & 2160.9 & $1.56^{\mathrm{ns}}$ \\
Res & 45 & 1381.1 & \\
Total & 59 & & \\
& & & \\
\hline Cochran's test & \multicolumn{3}{l}{$0.6764, P<0.01$} \\
Transformation & \multicolumn{3}{c}{ None } \\
\end{tabular}

482

483

484

485

486

487

488

489

490

491 


\section{Figure captions}

493 Fig. 1. Linear growth (A) and variation in wet weight $(B)$ and number of dichotomies (C)

494 and receptacles (D) (mean number \pm SE, $n=6$ ) associated with Horizontal (=procedural 495 controls), Vertical and Control treatments.

496 Fig. 2. Relative water content (RWC) of adult plants associated with horizontal and vertical 497 slope across time. Each line represents an individual.

498 Fig. 3. (A) Survivorship (Mean \pm SE, $n=8$ ) of $F$. spiralis germlings associated with 499 horizontal and vertical slopes; (B) Weight loss (Mean \pm SE, $n=5$ ) of plaster discs with 500 horizontal and vertical slopes across time.

501 Fig. 4. Number of recruits (Mean $+S E, n=5$ ) of $F$. spiralis found at increased distances 502 from adults.

503

504 
Fig. 1. Cacabelos et al.
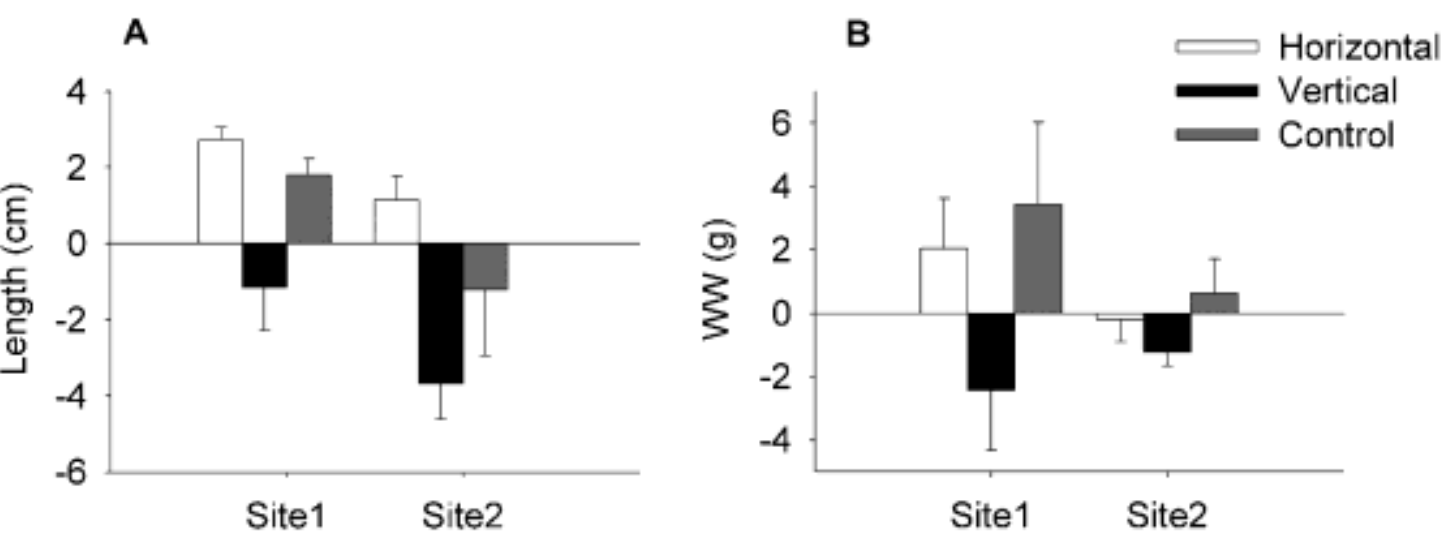

506
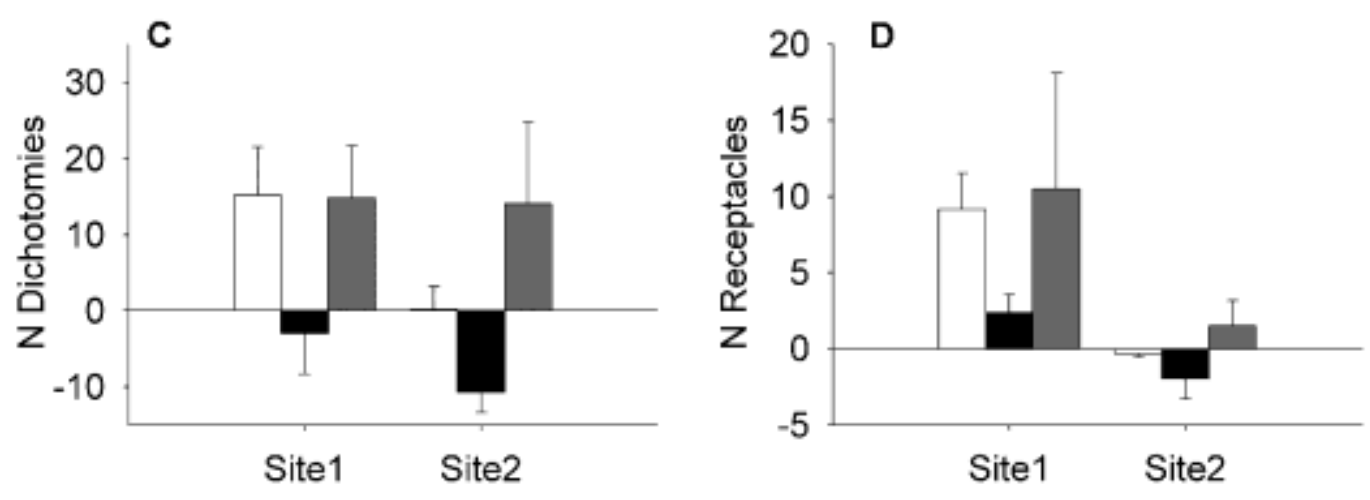

507

508 
Fig. 2. Cacabelos et al.
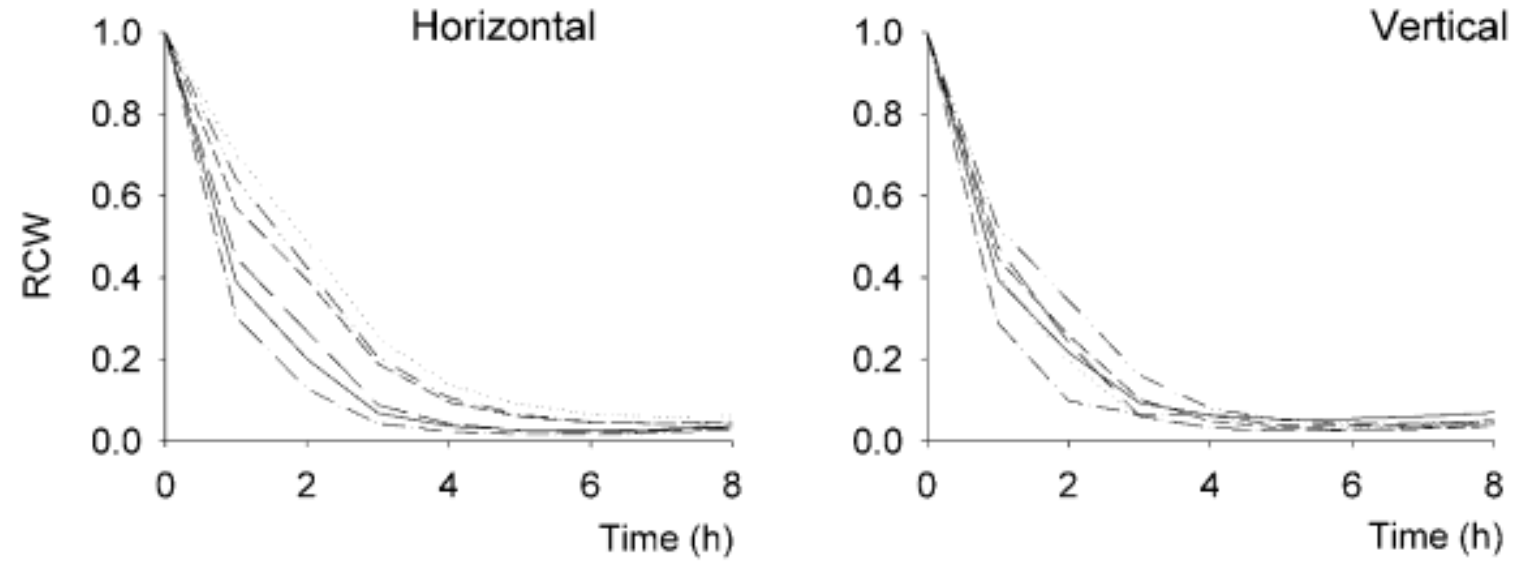

510

511

512

513

514

515 
Fig. 3. Cacabelos et al.

A

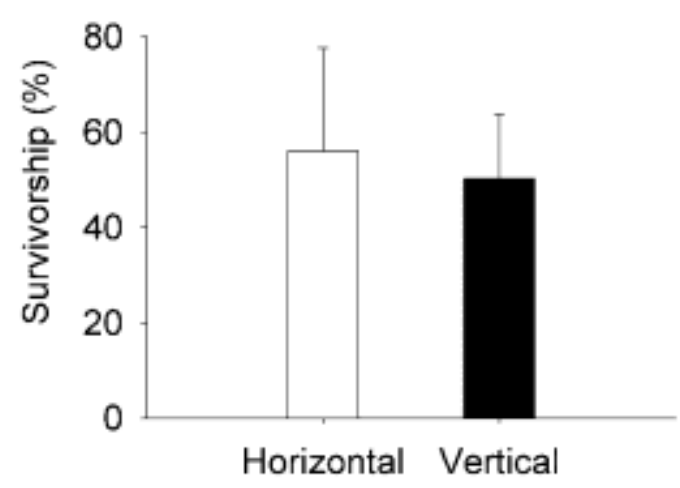

516

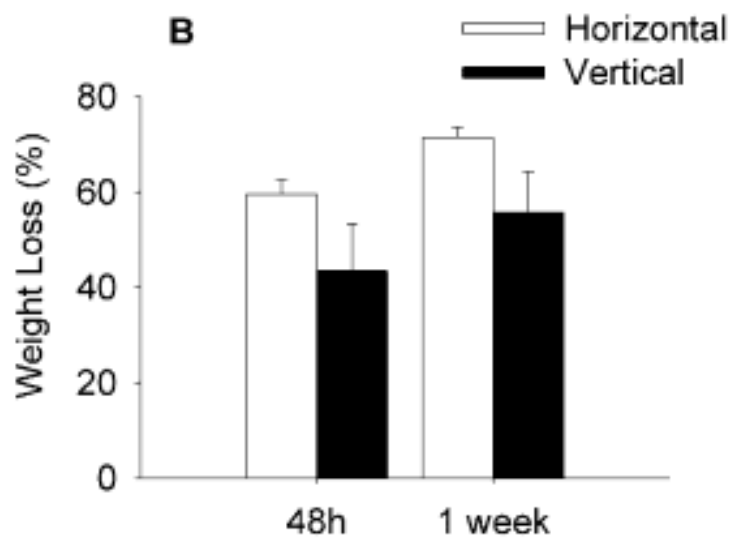

517

518

519

520

521

522 
Fig. 4. Cacabelos et al.

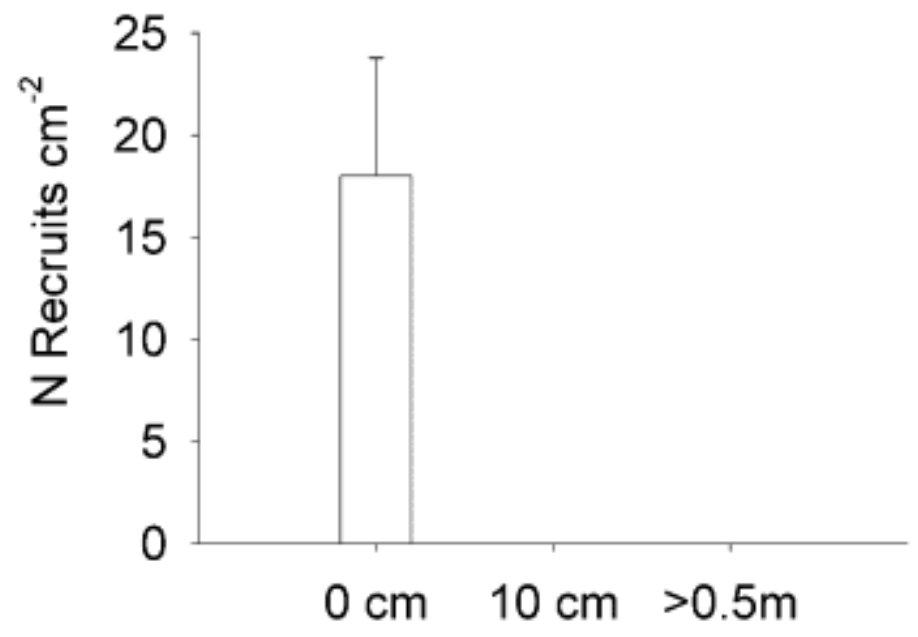

